\title{
Investigation of the Incidence of Coital Incontinence in Incontinent Women
}

\author{
Omer DEMIR ${ }^{1}$, Cihan COMBA ${ }^{2}$
}

Erzurum, Turkey

\section{ABSTRACT}

OBJECTIVE: Coital incontinence is the involuntary leakage of urine during sexual intercourse and is rarely reported in women with urinary incontinence. The aim of this study is to investigate the frequency of coital incontinence and its association with incontinence types.

STUDY DESIGN: All sexually active women with urinary incontinence (diagnosed as self-reported) attending the out-patient gynecology clinic of a regional state hospital were interviewed consecutively between September 2017 and September 2018 about their experience with regards to coital incontinence. The clinical evaluation consisted of medical history, physical examination, and urine analysis. The SPSS 20 program designed for Windows was used for statistical analysis.

RESULTS: Twenty-two of the 64 women who participated in the study were diagnosed with coital incontinence and the remaining 42 women were to be compared. 42 women were included in the control group, and 22 women were defined as the study group. The women with coital incontinence had significantly higher stress test positivity than the control group $(p=0.00)$. No significant differences in the frequency of coital incontinence between incontinence types were found. The chi-square test was applied, and the $p$-value was $>0.05(p=0.110)$. So there was no statistically significant relationship between the type of incontinence and the frequency of coital incontinence.

CONCLUSION: Coital incontinence is much more prevalent than expected and therefore patients with symptomatic urinary incontinence should be investigated for the presence of coital incontinence, as this may affect patient approach and treatment.

Keywords: Coital incontinence, Female sexual function, Women

Gynecol Obstet Reprod Med 2020;26(2):130-133

\section{Introduction}

Urinary incontinence (UI), the involuntary leakage of urine, is a common condition affecting $12-46 \%$ of the adult female population $(1,2)$. This condition is associated with a sig-

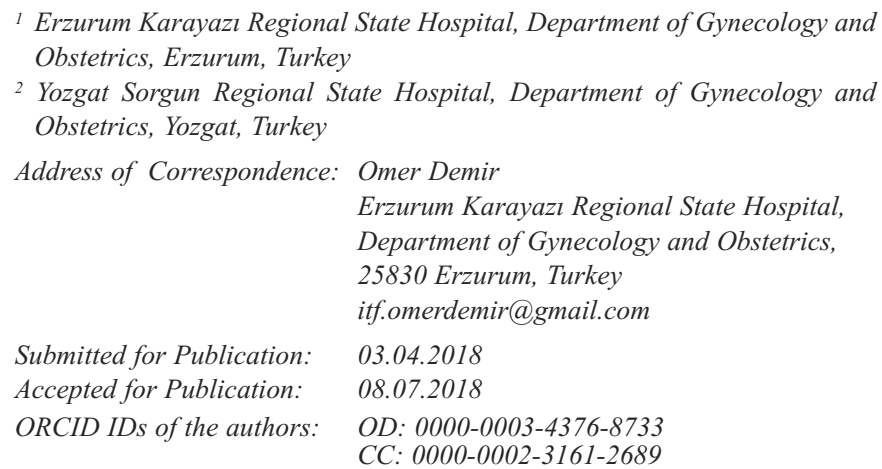

${ }^{I}$ Erzurum Karayazı Regional State Hospital, Department of Gynecology and Obstetrics, Erzurum, Turkey

2 Yozgat Sorgun Regional State Hospital, Department of Gynecology and Obstetrics, Yozgat, Turkey

Address of Correspondence: Omer Demir

Erzurum Karayazı Regional State Hospital,

Department of Gynecology and Obstetrics,

25830 Erzurum, Turkey

itf.omerdemir@gmail.com

Submitted for Publication: Accepted for Publication: ORCID IDs of the authors:

03.04 .2018

08.07 .2018

OD: 0000-0003-4376-8733

$C C: 0000-0002-3161-2689$

\begin{tabular}{|c|c|}
\hline \multirow{3}{*}{ 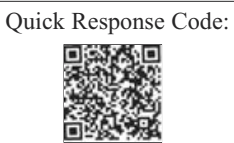 } & Access this article online \\
\hline & $\begin{array}{l}\text { Website: www.gorm.com.tr } \\
\text { e- mail: info@gorm.com.tr }\end{array}$ \\
\hline & DOI:10.21613/GORM.2019.948 \\
\hline
\end{tabular}

How to cite this article: Demir $O$. and Comba $C$. Investigation of the Incidence of Coital Incontinence in Incontinent Women. Gynecol Obstet Reprod Med. 2020;26(2):130-133 nificant deterioration in aspects of the quality of life, affecting social, physical, psychological, occupational, and sexual behaviors $(2,3)$. The three primary types of urinary incontinence are: stress urinary incontinence, urge urinary incontinence and mixed urinary incontinence as well as many different subtypes that are able to be defined. Stress urinary incontinence is most common, affecting up to $40 \%$ of all women (4).

Coital incontinence is the involuntary leakage of urine during sexual intercourse. The mechanisms of coital incontinence are poorly understood. The same can be said for any of the subtypes of incontinence. In this study, the aim was to investigate the frequency of coital incontinence and to determine its association with incontinence types.

\section{Material and Method}

All sexually active women with urinary incontinence (diagnosed as self-reported) attending the out-patient gynecology clinic of a regional state hospital were interviewed consecutively between September 2017 and September 2018 about their experience with regards to coital incontinence. The clinical evaluation consisted of medical history, physical examination, and urine analysis. Face-to-face interviews were con- 
ducted by the same clinician and assistant nurse in a quiet room at the clinic. The women were asked questions about their experiences with regards to coital incontinence. A 5point scale evaluated the frequency of coital incontinence (Never, Rarely, Sometimes, Often, and Always). Patients underwent pelvic examination for the staging of prolapse according to the pelvic organ prolapse quantification (POP-Q) system (5).

The local Ethics Committee approved the study. (Bakırkoy Dr. Sadi Konuk Education and Research Hospital-2019/15). All patients gave their informed consent to participate in this study and to respond to the forms, and their privacy was maintained. The study was created based on the principles set out in the Declaration of Helsinki.

\section{Statistical analysis}

The Statistical Package for the Social Sciences (SPSS) 20 program designed for Windows was used for statistical analysis. All continuous variables were defined as mean and standard deviations. Categorical variables were shown as a percentage of the total group. A p-value $<0.05$ was determined as statistically significant and all statistical tests were two-sided. Student's t-test and Mann-Whitney U test were used as independent tests. The Mann-Whitney $U$ test was used as a nonparametric alternative to the Student's t-test to compare the two groups. Statistical significance was analyzed using posthoc tests. Pearson's chi-square independence test and Fischer's exact test were used to examining the interdependence between the categorical data.

\section{Results}

Twenty-two of the 64 women who participated in the study were diagnosed with coital incontinence and the remaining 42 women were to be compared. 42 women were included in the control group, and 22 women were defined as the study group.

In the pelvic examinations of the patients in the study group and the control group, the POP-Q staging was below stage 2 , and there was no clinically significant prolapse.

All patients in the study were examined for urine analysis, and urinary tract infection was not detected.

The main demographic and clinical characteristics of these two groups are shown in table I.

The groups did not differ according to age, parity, cigarette usage, menopause status, birth type, and pelvic floor muscle strength value. The women with coital incontinence had a significantly higher stress test positivity than the control group $(p=0.00)$.

While none of the women with urge urinary incontinence were defined as having coital incontinence, a statistically significant percentage of those who experienced it was found in the stress urinary incontinence group $(p=0.00)$.

The Frequency of CI According to Incontinence Types:

No significant differences in the frequency of CI based on incontinence type were found. The chi-square test was applied, and the $\mathrm{p}$-value was $>0.05(\mathrm{p}=0.110)$. Consequently, there was no statistically significant relationship between the type of incontinence and the frequency of coital incontinence (shown in Table II).

Table I: Demographic and clinical characteristics or women with and without coital incontinence.

\begin{tabular}{|c|c|c|c|}
\hline & With coital incontinence $(n=22)$ & Without coital incontinence $(n=42)$ & $p$ value \\
\hline Age (range), yrs., mean \pm SD & $44.7 \pm 5.01(35-56)$ & $46.2 \pm 10.22(22-74)$ & $0.765^{a}$ \\
\hline Parity, mean \pm SD (median) & $6.13 \pm 2.29(6)$ & $5.9 \pm 2.06(6)$ & $0.151^{b}$ \\
\hline Cigarette usage, $\mathrm{n}(\%)$ & $11(50 \%)$ & $11(26.2 \%)$ & $0.057^{c}$ \\
\hline Postmenopausal, n (\%) & $11(50 \%)$ & $11(26.2 \%)$ & $0.035^{d}$ \\
\hline Stress test positivity, n (\%) & $16(72.7 \%)$ & $7(16.7 \%)$ & $<0.001^{c}$ \\
\hline Pelvic Floor Muscle Strength, & $2.68 \pm 0.57$ & $2.71 \pm 0.67$ & $0.631^{b}$ \\
\hline mean \pm SD Incontinence type, $n$ & & & $0.001^{\circ}$ \\
\hline SUI & $18(81.8 \%)$ & $15(35.7 \%)$ & \\
\hline UI & - & $13(31.4 \%)$ & \\
\hline $\mathrm{Ml}$ & $4(18.2 \%)$ & $14(33.4 \%)$ & \\
\hline Birth type, n & & - & $0.001^{c}$ \\
\hline Normal vaginal type & $19(86.4 \%)$ & $34(81 \%)$ & \\
\hline Cesarean type & - & $1(2.3 \%)$ & \\
\hline Normal vaginal + cesarean type & $3(13.6 \%)$ & $7(16.7 \%)$ & \\
\hline
\end{tabular}

a: Student's t-test, b:Mann-Whitney U test, c: Chi-squared test, d: Fisher's exact test 
Table II. Frequency of coital incontinence with regards to different types of incontinence

\begin{tabular}{llll}
\hline Frequency of Coital Incontinence & SUI $(n=18)$ & UUI & MUI $(n=4)$ \\
\hline Sometimes or rarely & $13(72.7 \%)$ & - & $3(75 \%)$ \\
Often & $4(22.2 \%)$ & - & - \\
Always & $1(5.6 \%)$ & - & $1(25 \%)$ \\
\hline
\end{tabular}

$p=0.110$ (Chi-squared test), SUI: Stress urinary incontinence, UUI: Urge urinary incontinence, MUI: Mixed urinary incontinence

\section{Discussion}

The primary objective of this study was to investigate the frequency of coital incontinence and its association with incontinence types in women attending a regional hospital.

The main findings are that coital incontinence was reported by approximately 1 in 3 incontinent women attending a gynecology clinic at a regional state hospital and is associated with avoidance of sexual activity. This study showed that the incidence of coital incontinence was up to $54 \%$ and was most prevalent in women with stress urinary incontinence. The most important reason for the high incidence of coital incontinence in our study was directly related to the questioning of only incontinent patients. In the literature, for example, Serati et al. reported that the percentage of coital incontinence did not exceed $27 \%$ (6). In three other studies in the literature, the incidence of coital incontinence did not exceed $24 \%$ $(3,7,8)$. However, if the prevalence of coital incontinence is assessed only in women with urinary incontinence, the rates have been shown to vary between $10 \%$ and $66 \%(9-12)$.

Patients are more likely to discuss their most basic complaints during their examination. In addition, they are generally shy about mentioning this complaint as they can see it as embarrassing unless it is explained that the complaint exists. Since one of the primary goals in this study was to reveal this, it was found to be significantly higher in the stress incontinence group.

This study also evaluated the frequency of coital incontinence among women with incontinence. Based on our data, $71 \%$ of the patients reported coital incontinence sometimes or rarely, $18 \%$ often, and $1 \%$ always. For patients who reported that they sometimes or rarely experience such symptoms, they did not see this as a reason for referral to the clinician as they did not see it as a general situation. Discounting these patients, the prevalence of coital incontinence was not so high. This study was the first study to investigate the presence of coital incontinence in incontinence patients and its effect on sexual functions in a state hospital which is not a tertiary urogynecology clinic.

The main weakness of this study, data on when coital incontinence occurred, either during penetration or orgasm, was not obtained. In the literature, many studies have been undertaken on this subject, and attempts have been made to gain in- sight into the etiology of coital incontinence. However, as this was not one of the aims of this study, the etiology was not questioned (12-15).

The sample size may need to be larger to generalize the findings. Restraints included the location of the study in a regional state hospital, as well as the reluctance for women to discuss the topic, and consequently more patients were unable to be included in the study. In conclusion, as shown in this study, coital incontinence is much more prevalent than expected. Therefore, it is necessary that the condition be the subject of greater focus and that patients be encouraged to discuss these problems more openly.

\section{Acknowledgment: None}

Funding statement: No funding was received for this study. Conflicts of Interest: The authors declare that they have no conflicts of interest.

Author contribution: OD: Project development, data collection, analysis, interpretation of data, manuscript writing, revising the manuscript. CC: Analysis, interpretation of data, manuscript writing, revising the manuscript

\section{References}

1. Abrams P, Cardozo L, Fall M, Griffiths D, Rosier P, Ulmsten U. et al. The standardisation of terminology of lower urinary tract function: report from the Standardisation Sub-committee of the International Continence Society. Neurourol Urodyn. 2002;21(2):167-78.

2. Thakar R. Review of current status of female sexual dysfunction evaluation in urogynecology. Int Urogynecol J Pelvic Floor Dysfunct. 2009;20(1):27-31.

3. Pauls RN, Segal JL, Silva WA, Kleeman SD, Karram MM. Sexual function in patients presenting to a urogynecology practice. Int Urogynecol J Pelvic Floor Dysfunct. 2006; 17(6): 576-80.

4. Hunskaar S, Lose G, Sykes D, Voss S. The prevalence of urinary incontinence in women in four European countries. BJU Int. 2004;93(3):324-30.

5. Bump RC, Mattiasson A, Bø K, Brubaker LP, DeLancey JO, Klarskov P, et al. The standardization of terminology of female pelvic organ prolapse and pelvic floor dysfunction. Am J Obstet Gynecol. 1996;175(1):10-7.

6. Serati M, Salvatore S, Uccella S, Nappi RE, Bolis P. Female urinary incontinence during intercourse: a review on an understudied problem for women's sexuality. J Sex 
Med. 2009;6(1):40-8.

7. Hilton P. Urinary incontinence during sexual intercourse: a common,but rarely volunteered, symptom. Br J Obstet Gynaecol. 1988;95(4):377-81.

8. Gordon D, Groutz A, Sinai T, Wiezman A, Lessing JB, David MP, et al. Sexual function in women attending a urogynecology clinic. Int Urogynecol J Pelvic Floor Dysfunct. 1999;10(5):325-8.

9. Jha S, Strelley K, Radley S. Incontinence during intercourse: myths unravelled. Int Urogynecol J. 2012;23 (5):633-7.

10. Espuña Pons M, Puig Clota M. Coital urinary incontinence: impact on quality of life as measured by the King's health questionnaire. Int Urogynecol $\mathrm{J}$ Pelvic Floor Dysfunct.2008;19(5):621-5.

11. El-Azab AS, Yousef HA, Seifeldein GS. Coital inconti- nence: relation to detrusor overactivity and stress incontinence. Neurourol Urodyn. 2011;30(4):520-4.

12. Serati M, Salvatore S, Uccella S, Cromi A, Khullar V, Cardozo L, et al. Urinary incontinence at orgasm: relation to detrusor overactivity and treatment efficacy. Eur Urol. 2008;54(4):911-5.

13. Urwitz-Lane R, Ozel B. Sexual function in women with urodynamic stress incontinence, detrusor over-activity, and mixed urinary incontinence. Am J Obstet Gynecol. 2006;195(6):1758-61.

14. Coksuer H, Ercan CM, Haliloğlu B, Yucel M, Cam C, Kabaca C, et al. Does urinary incontinence subtype affect sexual function? Eur J Obstet Gynecol Reprod Biol. 2011;159(1):213-7.

15. Khan Z, Bhola A, Starer P. Urinary incontinence during orgasm. Urology. 1988;31(3):279-82. 